\title{
SOME PROBLEMS IN THE RABBINIC USE OF THE QAL VA-CHOMER ARGUMENT
}

\author{
Hyam Maccoby*
}

Abstract: The qal va-chomer (a fortiori) argument is a logic of analogy, not of classes or sets (the subject-matter of Aristotelian logic), and this makes it suitable for legal, rather than scientific, argument. What makes it an exact reasoning is a special rule (unknown to Greek rhetorical use of a fortiori), namely the rule of dayyo, which lays down that the conclusion must not contain anything that was not present in the premises. For example: If a moderately good child deserves one sweet, a very good child all the more so deserves one sweet (correct); deserves two sweets (incorrect). Nevertheless, a qal va-chomer argument is not as unchallengeable as a syllogism, and the rabbis recognised various grounds of challengeablity. Especially interesting in this respect is the disagreement between the Sages and Rabbi Tarfon in Mishnah Bava Qamma 2:5. Is the qal va-chomer argument entirely logical, or does it contain an aspect of intuition? Can an argument be challengeable, yet rational? Is challengeability indeed a positive advantage in the search for rationality? This paper takes into account the view of the dayyo principle expressed in the Talmudic (Amoraic) discussion of b. Bava Qamma 25a, which makes it appear an arbitrary rule, rather than a principle of reasoning. This view is characterized as a falling-away from the more rational standpoint of the Mishnah. Also discussed is the relatively relaxed application of the rule of dayyo in aggadic discourse. An apparently flagrant breach of the rule in Mishnah Makkot 3:15, going far beyond the leniency of even aggadic discourse, is argued to be due to a mistranslation.

A prominent form of rabbinic reasoning is the qal va-chomer, or a fortiori argument, which in rabbinic hands reached a theoretical complexity and exactness that it never achieved in Greek thought. Yet this kind of reasoning too had a provisional, openended quality, for which it has been hailed by Susan Handelman (though perhaps not with complete justification) as a forerunner of the approach of deconstruction. ${ }^{1}$

The qal va-chomer is a reasoning appropriate to legal enquiry, rather than to natural science, but this does not mean that it is unscientific. It is a logic of analogy, not of classes or sets (the subject-matter of Aristotelian logic). It controls the rabbinic basic

\footnotetext{
* Hyam Maccoby (1924-2004), was at the Centre for Jewish Studies at the University of Leeds when he gave this lecture in 2001 to the Centre for Jewish Studies at the University of Manchester. Much of it can be found in modified form in Hyam Maccoby, The Philosophy of the Talmud (London: RoutledgeCurzon, 2002).

${ }^{1}$ Susan Handelman, The Slayers of Moses: The Emergence of Rabbinic Interpretation in Modern Literary Thinking (Albony: State University of New York Press, 1982), 52-57.
} 
legal enquiry, which is to consider different human situations and decide how alike or unlike they are, and thus how far legal conclusions can be transferred from one situation to another. The key phrase in qal va-chomer arguments is usually 'all the more so', introducing a conclusion. If a conclusion is true in a weak situation, it is true 'all the more so' in a strong situation.

To give a simple example: if a moderately good child deserves a sweet, what does a very good child deserve? Someone might answer, 'Two sweets', but this, in rabbinic thinking, would be wrong. The correct answer is, 'All the more so, a very good child deserves one sweet.' One must not go beyond the terms given in the premises, or one would be landed in uncertainty. This is the principle known as dayyo ('sufficient for it'), ${ }^{2}$ and it is this that lifts the qal va-chomer from the status of rhetoric to that of science. $^{3}$ The a fortiori argument is found in Greek rhetoric (e.g. Paul's Epistles, where the argument is conducted in Greek rhetorical style, without regard for the rule of dayyo $)^{4}$ but was never isolated or identified as a fully valid mode of argument in Greek theory of logic. It was Christian scholastics who gave it its Latin name, but did not enunciate the principle of dayyo.

A biblical source was found both for the qal va-chomer argument itself and for the rule of dayyo. This was the incident of the punishment of Miriam by leprosy, when God argues as follows: 'If her father had but spat in her face, would she not be ashamed seven days? Let her be shut out from the camp seven days, and after that let her be received in again.' (Numbers 12:14). The argument may be paraphrased as follows: if offending a father (a relatively light thing) is punished with banishment for seven days, offending God (a relatively heavy thing) should be punished all the more so with banishment for seven days. The Torah here provides an impeccable qal va-

\footnotetext{
${ }^{2}$ In full, dayyo lav'o min ha-din lihyot ke-nidon - note that here din means 'conclusion' while nidon means premise; the transliteration, often found, nadon is incorrect, as this is Biblical, not Mishnaic, Hebrew. See Marcus Jastrow, A Dictionary of the Targumim, the Talmud Babli and Yerushalmi and the Midrashic Literature (New York/Berlin: Verlag Choreb, 1926).

${ }^{3}$ See Heinrich Guggenheimer, 'Logical Problems in Jewish Tradition' in Philip Longworth, ed., Confrontations with Judaism (London: Blond, 1967), 181-185. See also Avi Sion, Judaic Logic, (Geneva: Editions Slatkine, 1995); Louis Jacobs, Studies in Talmudic Logic and Methodology (London: Valentine Mitchell, 1961).

${ }^{4}$ See Hyam Maccoby, The Mythmaker: Paul and the Invention of Christianity (London: Weidenfeld \& Nicolson, 1986), 64-67.
} 
chomer, studiously refraining from adding any days to Miriam's punishment beyond the number yielded by the rule of dayyo.

An example of qal va-chomer argument in rabbinic literature is the following (b. Bava Metzia 95a). It is stated in Exodus 22:14 that a borrower must pay the value of the borrowed article to the owner if it is destroyed or (in the case of an animal) dies. But what if the article or animal is stolen? Scripture does not tell us explicitly, but a qal va-chomer argument yields the answer, by analogy with the case of a paid guardian:

1. A paid guardian is free from payment if the article is destroyed, but is liable if it is stolen (Exodus 22:10-12).

2. Therefore, all the more so, a borrower, who is liable if the article is destroyed, should be liable if it is stolen.

The literal meaning of qal va-chomer is 'light and heavy'. The argument only works if there are two terms, one of which is 'heavier' (i.e. stronger) than the other. In this case, it is established that a borrower is 'heavier' (has more responsibility) than a paid guardian. This is proved from the Torah, but it also may be a matter of common sense. If you do someone a favour by allowing him the use of your property without payment, then you expect a higher standard of obligation and of recompense, in case of a disaster, than from someone who was not receiving a favour, but was merely looking after the object as a job, without being allowed personal use of the object. On the other hand, one might argue just the opposite: a person who is being paid to look after an article should be more vigilant than a person who is not being paid. This is the kind of refuting argument that is often used in the Talmud, which is by no means inclined to accept every proposed qal va-chomer argument. In the present case, the refuting argument would not get very far, since the Torah itself clearly regards the borrower as more liable than the paid guardian; but in many cases, this is not so clear, so there is much room for discussion. The qal va-chomer reasoning is open-ended, in that it depends on a distinction between 'light' and 'heavy' that is always open to question. This aspect, however, does not invalidate this type of reasoning, but differentiates it from the mathematical or logical kind of reasoning, where intuition or grasp of human values play no part. It is this undetermined character of the qal va- 
chomer argument that leads Susan Handelman to see it as in accordance with deconstructionist thinking. However, she lays no stress on the more formal and strict aspect embodied in the rule of dayyo. ${ }^{5}$ There are also other kinds of doubt that may enter into a qal va-chomer reasoning. An interesting example is this disagreement between Rabbi Tarfon and his fellow-rabbis, recorded in the Mishnah:

If an ox caused damage by 'horn' in a public domain, its owner pays halfdamages; but if in a private domain, Rabbi Tarfon says, 'Full damages', but the Sages say, 'Half damages'. Rabbi Tarfon said to them, 'In the case of 'foot' and 'tooth' there is leniency in the public domain (no damages imposed) and stringency in the private domain (full damages): therefore in the case of 'horn' where there is stringency in the public domain (half-damages) [this refers to the first two occasions of damage by 'horn'; on the the third occasion, the animal becomes 'confirmed' as aggressive, and its owner becomes liable to full damages, since he should have taken more care over the animal; 'foot' and 'tooth', however, are regarded as damage to be expected, and therefore the owner of the animal is fully responsible, except when the goods damaged have been carelessly left in the public domain], should not there be stringency (equal to that of 'foot' and 'horn') in the private domain?' They answered, 'It is enough if the inferred law is as strict as the law from which it is inferred: if 'horn' pays half-damages in the public domain, it should pay the same in the private domain.' He said to them, 'My inference is not from 'horn' to 'horn' but from 'foot' to 'horn'. If in the public domain there is leniency in the case of 'foot' and 'tooth' and stringency with 'horn', then if there is stringency for 'foot' and 'tooth' in the private domain, is it not logical that there should be stringency in the private domain for 'horn'?' They answered, 'It is enough if the inferred law is as strict as the law from which it is inferred: if 'horn' pays half-damages in the public domain, it should pay the same in the private domain.' 6

\footnotetext{
${ }^{5}$ Handelman, The Slayers of Moses, 52-57. For more general criticism of Handelman on the relationship between rabbinic exegesis and modern literary theory, see David Stern, 'Literary Criticism or Literary Homilies? Susan Handelman and the Contemporary Study of Midrash', Prooftexts 5 (1985), 96-103; David Stern, Midrash and Theory: Ancient Jewish Exegesis and Contemporary Literary Studies (Evanston: Northwestern University Press, 1996).

${ }^{6}$ Mishnah Bava Qamma 2:5.
} 
It should be noted that this argument is not about the validity of the principle of dayyo in qal va-chomer arguments, as some scholars have mistakenly thought. Both Rabbi Tarfon and his opponents the Sages accept not only the validity of qal va-chomer, but also the validity of its limiting principle of dayyo. Where they differ, in this instance, is how to draw up the list of terms involved in the reasoning. The Sages do not want to admit 'foot/tooth' as one of the two terms in the reasoning (though they still lie in the background as providing the basis for the light/heavy dichotomy); instead they wish to confine the main steps of the reasoning to 'horn' - the two terms involved are 'horn-in-the-public-domain' and 'horn-in-the-private-domain'. Rabbi Tarfon, however, wishes to extend the basic reasoning to 'foot/tooth' (they may be regarded as one term here, since their law is identical in this context). The two terms of his reasoning are thus 'horn' and 'foot/tooth', and the distinction between public and private domain is applied to both terms. Thus Rabbi Tarfon is not admitting that he is making an unjustified leap from 'half-damages' to 'whole-damages' in the case of 'horn'. He is moving from 'whole-damages-in-the-private-domain' (in the case of 'foot/tooth) to 'whole-damages-in-the-private-domain' (in the case of 'horn'). The Sages, however, see something illegitimate about this move, since, in the process, 'horn' has been surreptitiously promoted from 'half-damages' to 'whole-damages', which appears to be a breach of the principle of dayyo. We see from this that in a qal $v a$-chomer argument there may sometimes be an uncertainty arising from the choice of appropriate terms. This choice of terms may be a matter of intuition, rather than strict logic, and thus one person's valid qal va-chomer may be another's fallacy. This does not mean that this method of argument should be condemned as subjective, but only that it belongs to the area of rationality rather than strict logic. A method of reasoning can be enormously useful even if it gives rise at times to irreconcilable disagreements. 'The how much more so is a relation of likeness which depends on an if, not an is, and therefore conclusions are always relative and are subject to further interpretation and application. There are no categorical statements or proofs in a demonstration which preclude further discussion. The if always remains apparent, and subject to further revision and extension. ${ }^{7}$ There is, after all, a way to reconcile such differences among people who are not too dogmatically attached to their own opinions - by majority vote. In this instance, the vote went against Rabbi Tarfon, and

\footnotetext{
${ }^{7}$ Handelman, The Slayers of Moses, 56.
} 
he no doubt accepted the decision in practice, though there was nothing to stop him from continuing to hold his opinion in theory.

Thus rabbinic logical theory anticipates modern scientific theory in some respects (especially in the binyan 'av) but in other respects (especially the qal va-chomer) it enters a region of logic that transcends the usual parameters of Western logic. The Amoraic discussion of the Mishnah (b. Bava Qamma, 25a) must be discounted, since it shows no comprehension of the logical force of the dayyo principle. Instead, it imagines that the rule is an arbitrary fiat of the Torah, by which the conclusion of a qal va-chomer reasoning is cut in half (why by precisely a half is not explained). Thus in the case of Miriam (the proof-text, Numbers 12:14), it was really to be expected that God would banish her for 14 days (twice the number of days she would have expected from an angry human father), but the Torah cut this expected number by half. The Gemara then explains that Rabbi Tarfon, while acknowledging the rule of dayyo, had a variant view of it which would exclude the present case (he considered that a qal va-chomer that, by the application of dayyo, yields a result already derivable from other sources is not subject to the rule of dayyo). This implausible account ignores totally the plain reason which Rabbi Tarfon himself gives in the Mishnah: that he was using different terms as the basis for his reasoning from those used by the Sages. It ignores also the fact that Rabbi Tarfon's expressions in the Mishnah show that he is not arguing that this instance is exempt from the rule of dayyo but, on the contrary, that he is bringing it into the rule. It seems that in the Amoraic period the rationale of the dayyo rule, perfectly understood in earlier times, had been lost. In earlier times, too, the derivation of the rule from Scripture (if made, which is doubtful) was not intended to give it the status of an arbitrary fiat, but to give authoritative approval to a deliverance of reason. Unfortunately, medieval commentators on the Mishnah reproduce the Amoraic discussion. ${ }^{8}$ Heinrich Guggenheimer gives a cogent account of the dayyo rule in terms of pure logic, saying that, in virtue of this rule, the qal vachomer argument is 'an admirable solution (the only one known to me) of the problem of making an analogy an exact reasoning'. ${ }^{9}$ Guggenheimer also gives a rendering of the qal va-chomer in the terminology of modern mathematical logic. $\mathrm{He}$ does not mention, however, the Amoraic discussion which takes the rule of dayyo out

\footnotetext{
${ }^{8}$ See Talmudic Encyclopaedia (Hebrew), s.v. dayyo lav'o min ha-din lihyot ke-nidon.

${ }^{9}$ Guggenheimer, 'Logical Problems in Jewish Tradition', 181-85.
} 
of the realm of logic, or the considerable medieval discussion based on b. Bava Qamma 25a.

\section{The Parodic Qal va-Chomer}

Perhaps because of the flexible, open-ended nature of the qal va-chomer argument, we find in the rabbinic sources a rather surprising phenomenon - instances of the argument which are not meant to be taken seriously, and comprise a kind of parody of the argument. An example is found in b. Sanh. 17a. Here it is said that one of the qualifications of a member of the Sanhedrin was the ability to prove that the body of a reptile (sheretz) was clean, i.e. did not convey ritual impurity. This would seem an impossible undertaking, since the Torah says explicitly that it is unclean. However, in response to the assertion, Rav offered to prove this impossible proposition by means of a qal va-chomer argument. It ran as follows: the dead body of a snake does not convey impurity. Yet a snake is the means of spreading impurity, for it causes many deaths. How much more so should a reptile (which is harmless) be regarded as not causing impurity! This same argument is attributed to Ravina in b. Eruvin 13b. The Gemara immediately refutes this argument by denying the 'heaviness' of the heavy term. Being a cause of impurity indirectly by causing death has nothing to do with causing impurity by direct contact. Otherwise, we would have to regard a thorn as a cause of impurity by contact, since it may cause death to someone who becomes impaled on it. Clearly, this qal va-chomer argument was meant simply as an exercise, perhaps even an exercise in how to refute a faulty qal va-chomer.

Sometimes, however, constructing a faulty qal va-chomer deliberately was regarded with distinct disfavour, not merely as an interesting exercise. It is recorded that a certain rabbi (Rabbi Jose ben Taddai of Tiberias) was actually excommunicated for presenting a frivolous qal va-chomer argument, since this was held to bring rabbinic methods of argument into disrepute (Derekh Eretz Rabba, 1). The condemned argument was as follows: I am forbidden to marry my daughter; yet her mother is permitted to me. All the more so, I should be forbidden to marry the daughter of someone who is forbidden to me. My neighbour's wife is forbidden to me; therefore I should be forbidden to marry her daughter. Therefore all marriages should be forbidden except to the daughters of unmarried mothers, widows or divorced women. 
No formal refutation of this argument was offered: the response was to kick its perpetrator out of the academy!

Of course, it is possible to produce parodies even of syllogistic arguments - many such were produced in the Middle Ages. Perhaps we should attribute such parodies merely to high spirits, not to any flaw in the type of argument itself. But such arguments do point to features of the argument which require care when the argument is used seriously. There is, however, a certain acknowledgment of the vulnerability of the qal va-chomer in general in the dictum that it should never be used to impose an extra penalty not explicitly mentioned in the Torah ('ein 'oneshin min ha-din, b. Sanh. 54a and frequently). The qal va-chomer is acknowledged to be a purely human reasoning, and as such to be always open to criticism and to have limited authority.

\section{Qal va-Chomer in Aggadah}

An apparently glaring infringement of the rule of dayyo is in Mishnah Makkot, 3:15:

Moreover R. Hananiah ben Gamaliel said: If he that commits one transgression thereby forfeits his life, how much more, if he performs one religious duty, shall his life be given to him! ${ }^{10}$

This is a very feeble argument, and it also seems inconsequential, since it does not show any connection with R. Hananiah's immediately preceding remark that those who are condemned to 'cutting off' (karet) can escape this punishment by undergoing flogging (malqut). Rashi therefore feels constrained to provide an elaborate explanation, based on the notion that reward for good deeds is much greater (at least 2000 times greater, he argues on the basis of a proof-text) than punishment for transgression. Rashi thus seems to imply that the usual rule for a qal va-chomer can be ignored, since there is such a gap between the two terms 'transgression' and 'performance'. This, however, might possibly be granted if the conclusion echoed the premise, but it does not. The premise speaks of forfeiting life, and the conclusion speaks of gaining life. No amount of weighting can turn a negative premise into a positive conclusion. If another method of argument were used (instead of the qal va-

\footnotetext{
${ }^{10}$ Danby translates 'forfeits his soul' and 'his soul will be restored to him'. Herbert Danby, The Mishnah (Translated from the Hebrew with introduction and brief explanatory notes) (Oxford: Clarendon Press, 1933), 408. However, this is unwarranted, since in context karet is being interpreted as death by the hand of God, not as some spiritual punishment to the soul in the after-life. Moreover, tinaten means 'will be given', not 'will be restored'.
} 
chomer) some semblance of consecutive reasoning can be achieved, e.g. If a man who commits a transgression forfeits his life, it seems reasonable that the opposite behaviour, the fulfilment of a commandment, will produce opposite results, namely the gaining of life, especially if we know that reward is always far greater than punishment. But this reasoning by opposites is not a qal va-chomer, and Rabbi Hananiah makes it crystal clear (by his use of how much more) that he is attempting a qal va-chomer.

Another line of exegesis (see Bertinoro on the Mishnah) ${ }^{11}$ tries to provide some continuity between Rabbi Hananiah's first and second sayings, such continuity being demanded by the conjunction ve linking the two sayings (in the Gemara Mishnah; the conjunction may have been omitted in editions of the Mishnah under the influence of exegetes, also quoted by Bertinoro, who denied any continuity between the two sayings of R. Hananiah). This interpretation sees the one 'who fulfils the commandment' as none other than the one who transgressed a karet law, but later repented and accepted flogging as his punishment, thereby escaping the heavier punishment of death by the hand of God. Rabbi Hananiah's second saying thus becomes: If one who transgresses forfeits his life, how much more so shall one who accepts punishment (thereby performing a commandment) escape with his life. Here there is certainly some continuity, but the faultiness in the qal va-chomer argument has not been remedied. The negative in the premise has turned into a positive in the conclusion, and the argument, if valid, is an argument by opposites not by qal vachomer.

I suggest a very simple solution to all these problems. The expression notel nafsho has been wrongly translated by all commentators as 'forfeits his life', but is much better translated as 'receives his life'. The verb natal can mean either 'to remove' or 'to receive'. ${ }^{12}$ If the meaning here is 'remove', then the expression should be notelin nafsho, 'they remove (or 'one removes') his life', for the singular verb notel would signify that he takes or removes his own life, and no one is suggesting that we are concerned here with suicide. I am suggesting, in other words, that the expression notel

\footnotetext{
${ }^{11}$ Obadiah of Bertinoro, Mishnah: Text with Commentary of Rabbi Obadiah of Bertinoro (Jerusalem: Bloch Publishing Company, 1947). Original 1548, Venice.

${ }^{12}$ See Marcus Jastrow, A Dictionary of the Targumim, the Talmud Babli and Yerushalmi and the Midrashic Literature (New York/Berlin: Verlag Choreb, 1926), 899.
} 
nafsho means the exact opposite of what commentators have thought it to mean. With this correction, the difficulties of continuity and logic disappear. The translation of R. Hananiah's second saying now becomes: 'If he that commits one transgression (i.e. the transgressor of a karet law) receives his life (i.e. has his sentence commuted from death by the hand of God to flogging), how much more so will one who performs a commandment be given his life!' This is a perfectly valid qal va-chomer argument, since no term in the conclusion fails to appear in the premise. Also, the continuity is also excellent, since R. Hananiah's second observation is indeed a reflection based on his first. The unconvincing idea (quoted by Bertinoro), aimed at continuity, that it is the transgressor who is the performer of a commandment is eliminated. The transgressor is indeed a transgressor, yet he preserves his life; how much more so should someone who is not a transgressor but a performer of a commandment preserve his life!

It may be objected that if the two expressions notel nafsho and yinaten lo nafsho have identical import, why is the expression varied in this way? The reason may be merely stylistic. The person who, against the odds, having been condemned to death, is reprieved, snatches at this unexpected relief and is made the subject of an active verb of receiving. The person who has deserved reward waits for his due without desperation and is content to have it bestowed on him. This variation in expression does not affect the logic of the argument.

On the other hand, it may be objected that the rules of the qal va-chomer, and especially the rule of dayyo (that the conclusion must not contain any term not contained in the premise) is not so strictly applied in aggadic as opposed to halakhic reasonings, and that therefore R. Hananiah's argument should not be subjected to such severe criticism. There is truth in this, and an example of what appears somewhat loose aggadic qal va-chomer reasoning is to be found, as it happens, in this very same Mishnah. R. Shimon ben Rabbi reasons: abstaining from blood, which causes revulsion, brings reward; all the more, abstaining from robbery and incest, which the soul longs for, should bring reward for all generations to come up to the end of the world. The last part of this reasoning constitutes a breach of dayyo, for nothing was said in the premise about all generations to come. Yet in this reasoning, faulty as it is by halakhic standards, the actual terms are not changed from premise to conclusion. 
There is only an intensification of the conclusion, in an enthusiastic, homiletic style. Even in aggadic reasonings, the rules are never so flagrantly breached as in R. Hananiah's saying, in its usual interpretation. It is therefore justifiable to look for another interpretation.

\section{BIBLIOGRAPHY}

Obadiah of Bertinoro, Mishnah: Text with Commentary of Rabbi Obadiah of Bertinoro (Jerusalem: Bloch Publishing Company, 1947). Original 1548, Venice.

Herbert Danby, The Mishnah, translated from the Hebrew with introduction and brief explanatory notes (Oxford: Clarendon Press, 1933).

Susan Handelman, The Slayers of Moses: The Emergence of Rabbinic Interpretation in Modern Literary Thinking (Albany: State University of New York Press, 1982).

Heinrich Guggenheimer, 'Logical Problems in Jewish Tradition' in Philip Longworth, ed., Confrontations with Judaism (London: Blond, 1967).

Louis Jacobs, Studies in Talmudic Logic and Methodology (London: Valentine Mitchell, 1961).

Marcus Jastrow, A Dictionary of the Targumim, the Talmud Babli and Yerushalmi and the Midrashic Literature (New York/Berlin: Verlag Choreb, 1926).

Hyam Maccoby, The Mythmaker: Paul and the Invention of Christianity (London: Weidenfeld \& Nicolson, 1986).

Avi Sion, Judaic Logic (Geneva: Editions Slatkine, 1995).

David Stern, 'Literary Criticism or Literary Homilies? Susan Handelman and the Contemporary Study of Midrash', Prooftexts 5 (1985), 96-103.

David Stern, Midrash and Theory: Ancient Jewish Exegesis and Contemporary Literary Studies (Evanston: Northwestern University Press, 1996). 